\title{
Analysis of growth-phase regulated genes in Streptococcus agalactiae by global transcript profiling Izabela Sitkiewicz ${ }^{1,3}$ and James M Musser*1,2
}

Address: ${ }^{1}$ Center for Molecular and Translational Human Infectious Diseases Research, The Methodist Hospital Research Institute, Houston, Texas 77030, USA, ${ }^{2}$ Department of Pathology, The Methodist Hospital, Houston, Texas 77030, USA and ${ }^{3}$ National Medicines Institute, Dept. of Epidemiology and Clinical Microbiology, Chelmska 30/34, 00-725 Warsaw, Poland

Email: Izabela Sitkiewicz - iza.sitkiewicz@gmail.com; James M Musser* - jmmusser@tmhs.org

* Corresponding author

Published: 10 February 2009

BMC Microbiology 2009, 9:32 doi:10.1/86/147|-2180-9-32
Received: 9 May 2008

Accepted: 10 February 2009

This article is available from: http://www.biomedcentral.com/I47I-2/80/9/32

(c) 2009 Sitkiewicz and Musser; licensee BioMed Central Ltd.

This is an Open Access article distributed under the terms of the Creative Commons Attribution License (http://creativecommons.org/licenses/by/2.0), which permits unrestricted use, distribution, and reproduction in any medium, provided the original work is properly cited.

\begin{abstract}
Background: Bacteria employ multiple mechanisms to control gene expression and react to their constantly changing environment. Bacterial growth in rich laboratory medium is a dynamic process in which bacteria utilize nutrients from simple to complex and change physical properties of the medium, as $\mathrm{pH}$, during the process. To determine which genes are differentially expressed throughout growth from mid log to stationary phase, we performed global transcript analysis.

Results: The $S$. agalactiae transcriptome is dynamic in response to growth conditions. Several genes and regulons involved in virulence factor production and utilization of alternate carbon sources were differentially expressed throughout growth.

Conclusion: These data provide new information about the magnitude of plasticity of the $S$. agalactiae transcriptome and its adaptive response to changing environmental conditions. The resulting information will greatly assist investigators studying $S$. agalactiae physiology and pathogenesis.
\end{abstract}

\section{Background}

Bacteria employ multiple mechanisms to control gene expression and react to their constantly changing environment. These processes are especially critical for bacterial pathogens to survive and cause disease in humans and other hosts. Global control of gene expression is achieved using alternative sigma factors, two-component systems (TCSs), small regulatory RNAs, regulators such as RelA and LuxS, or concerted action of regulons (for a review see [1-6] and references therein). Gram positive pathogens such as group A Streptococcus (S. pyogenes, GAS) and group B Streptococcus (S. agalactiae, GBS) lack (or have limited number) of alternative sigma factors of fully confirmed function [7-9]. Analyses of global transcription in GAS under various growth conditions including saliva, blood, and tissue has shown that environmental response regulation is achieved using other mechanisms such RNA stability [10], "stand alone" regulators such as $m g a$ [11], or TCSs [12-15]. These transcriptome analyses have been especially useful in providing new information about microbial physiology and leads for pathogenesis research. However, the transcriptional response of GBS to changing growth conditions has not been fully analyzed, only single reports were recently published [16]. GBS is an important human and cow pathogen, responsible for thousands of severe invasive infections in man and large economic loss attributable to bovine mastitis (see $[17,18]$ and references therein). 
One of the best examples of sequential gene regulation is bacterial growth in complex medium and activation of stationary phase genes. During growth, bacteria utilize available nutrients, presumably from simple to more complex, and alter their environment (e.g. decrease or increase in $\mathrm{pH}$ ) as a result of metabolic byproduct release. Therefore, stationary phase can be considered the acid/ alkali stress, depending on the type of metabolism and nutrients utilized. GAS grown to stationary phase sequentially expresses genes involved in various aspects of GAS physiology, metabolism and virulence, many genes activated or repressed during the transition to stationary phase have also been shown to play a role in GAS virulence [19]. The purpose of the present study was to identify growth phase-regulated genes in GBS, with a special interest in providing new information about virulence factor gene expression.

\section{Methods}

\section{Sample collection for microarray analysis}

GBS strain NEM316 [7] was grown as three static cultures (3 biological replicates) in liquid Todd Hewitt medium with $0.5 \%$ yeast extract in the $5 \% \mathrm{CO}_{2}$ atmosphere at $37^{\circ} \mathrm{C}$ [12]. Samples were collected at $\mathrm{OD}_{600}$ approximately $0.5,1.0,2.0$ and 2.5, representing mid-logarithmic (ML), late-logarithmic (LL), early stationary (ES) and stationary ( $\mathrm{S}$, about $3 \mathrm{~h}$ from entering the phase) growth phases, respectively. Growth curve of bacterial cultures used for data collection is presented as Figure 1. Five $\mathrm{ml}$ of each sample were immediately mixed after collection with $10 \mathrm{ml}$ of RNAProtect (Qiagen), centrifuged and stored at $80^{\circ} \mathrm{C}$ until processing.

Glucose content of the medium at the beginning and end of the culture was measured using Optium Xido glucometer (Abbot) and $\mathrm{pH}$ was checked using $\mathrm{pH}$ test strips (Macherey Nagel).

\section{RNA isolation}

GBS cells were mechanically opened by shaking with glass beads (Lysing Matrix B, MPBio) and TRIZOL (Invitrogen). RNA was isolated according to Chomczynski and Sacchi [20], with an additional purification step using RNeasy columns (Qiagen). Targets for hybridization with the array were prepared according to array manufacturer (Affymetrix) as described previously [12].

\section{Array hybridization and data acquisition}

The custom expression array manufactured by Affymetrix [21] contained redundant sets of probes representing 1,994 open reading frames (ORFs) of previously sequenced GBS strain NEM316 [7]. Arrays were hybridized and scanned according to the manufacturers instructions. The results of hybridization were normalized to mean of total intensity of GBS probes to allow multiple

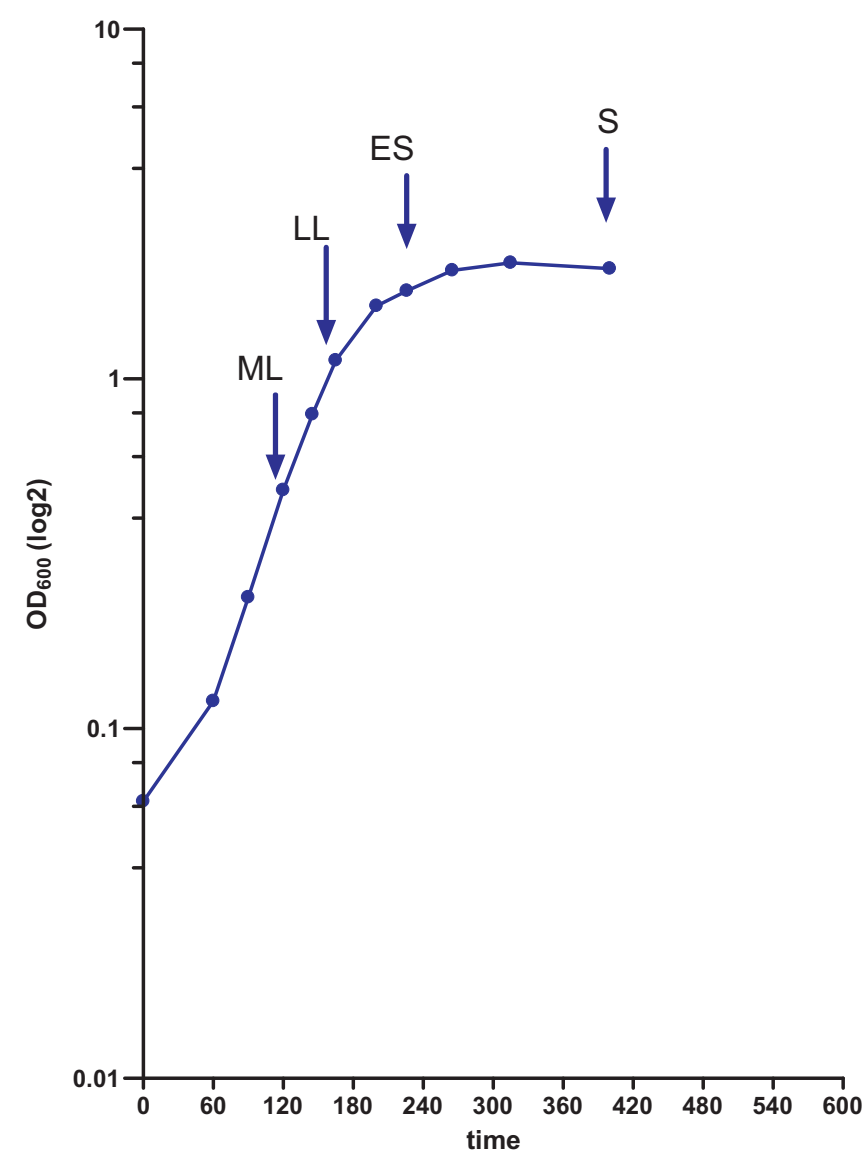

Figure I

Growth curve of NEM3 I 6 in THY medium. Arrows denote points of sample collection.

time point comparison. Array hybridization results are presented as Additional file 1 and are deposited in GEO database http://www.ncbi.nlm.nih.gov/projects/geo/ under GSE12238 accession number.

\section{Results and Discussion \\ General trends in transcription}

After determining transcript levels for all probe sets, the 1,994 transcripts were grouped into 15 clusters based on their behavior during growth (Figure 2) (self organizing map algorithm; Array Assist 5.1.0 package, Stratagene). The clusters were grouped into five main categories. The first 3 categories contain genes whose transcription did not correspond to growth phase, and were either expressed at low (cluster 0), medium (clusters 6,7), or high (clusters 8,9 ) levels in all phases of growth. Category 4 genes (clusters 1-4) exhibited increased transcription in ES or S phase, and category 5 genes (clusters $5,10-14$ ) had transcription levels that peaked in ML phase and decreased into $S$ phase. 


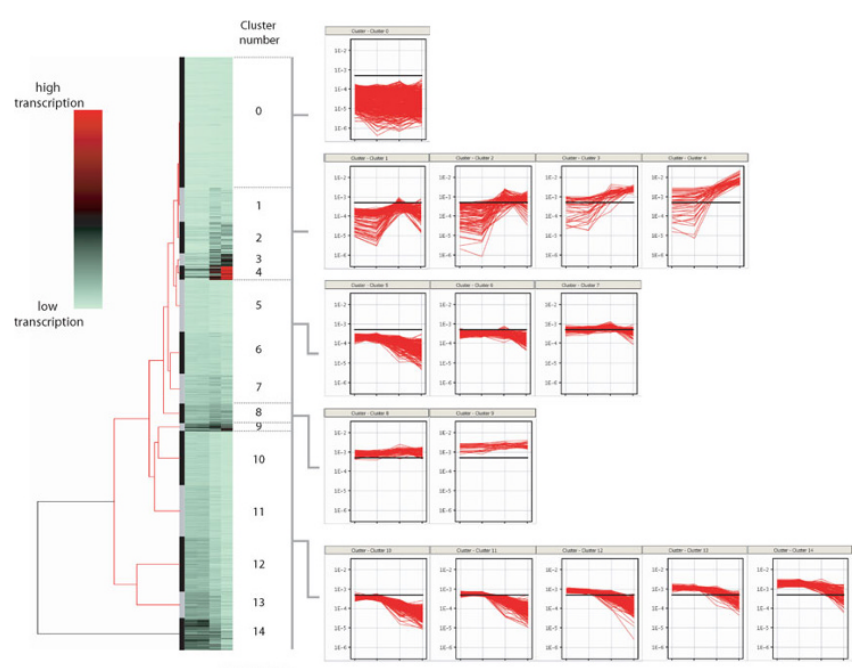

Figure 2

Grouping of S. agalactiae transcripts into distinct I 5 clusters based on expression profiles from ML to $S$

growth phases. The dendrogram and clusters were generated using a self organizing map algorithm and represent changes in expression of I,994 transcripts at four consecutive time points: $\mathrm{ML}, \mathrm{LL}, \mathrm{ES}$, and $\mathrm{S}$ phases. Cluster 0 genes had low level of transcription. Clusters $\mathrm{I}-4$ genes positively correlated with stationary phase of growth transcription level and peaked in the ES (clusters I and 2) or S (clusters 3 and 4) phase of growth. Clusters 5 and 10-14 are negatively correlated with the $S$ phase of growth; transcription of genes grouped in these clusters reached their peak in ML phase and decreased in S phase. Genes in clusters 6-9 are expressed relatively steadily during growth although at various levels of expression, ranging from very high (cluster 9) to mid-low (cluster 6). The black horizontal line on the cluster graphs represents average transcription level of the complete dataset. The transcript level in each cluster is plotted using a logarithmic scale. Number of transcripts in clusters: Cluster 0 , 440; Cluster 1, I 15; Cluster 2, 106; Cluster 3, 42; Cluster 4, 47; Cluster 5, 175; Cluster 6, 140; Cluster 7, 100; Cluster 8, 66; Cluster 9, 26; Cluster 10, 183; Cluster II, 173; Cluster 12, I85; Cluster 13, 89; Cluster 14, 107.

Genes exhibiting growth phase-independent transcription Genes in clusters 6, 7, 8, and 9 did not show growth phase-dependent transcriptional regulation. The genes are clustered instead based on their transcript level and general profile. Clusters 6 and 7 contain genes that are expressed at the same level until ES phase to slightly lower expression in $\mathrm{S}$ phase. Clusters 8 and 9 contain genes, which the transcript level is steady or slightly increases over time. Cluster 9 is especially interesting in that it contains a group of highly expressed genes that includes $\mathrm{fabF}$, $f a b Z, f a b H$, and $a c c B C D$ (gbs0331, 0336-0341) encoding subunits of beta-ketoacyl-ACP synthase, subunits of acetyl-CoA carboxylase, 3-hydroxydecanoyl-ACP dehydratase, and biotin carboxylase. Other genes in cluster 9 involved in energy production are ATP synthase subunits (atpABEF, gbs 0875-7 and 9). Interestingly, cluster 9 contains a transcript of putative catabolite control protein $\mathrm{A}$ $(c c p A)$, and the amount grows steadily to increase about three-fold in $S$ phase in comparison with ML (Table 1). $\mathrm{CcpA}$ is a major mediator of carbon catabolite repression - the control mechanism of nutrient utilization. In GAS, CcpA has recently been shown to be a critical direct link between carbohydrate utilization and virulence [21]. Function of CcpA in GBS has been not experimentally confirmed yet. Based on the consensus CcpA binding site (cre sequence), we detected that genome of NEM316 strain contains multiple putative cre sites in promoter sequences of multiple genes (Table 2), what might be correlated with changes in expression of genes involved in arginine and carbohydrate metabolism (see below). The transcript encoding HPr carrier protein, another element of the CcpA regulatory pathway in Gram-positive bacteria, also belongs to cluster 9. HPr kinase, however, is an $\mathrm{S}$ phase-related gene (see below).

\section{Log phase related genes}

Almost 50\% of all GBS transcripts that were represented on the chip had similar patterns of expression and were classified into clusters 5, 10,11, 12, 13, and 14. Transcript levels peaked in ML phase and decreased gradually to their lowest levels in S phase. These six clusters differ in their basal level of expression in $\mathrm{L}$ phase. The genes assigned to cluster 5 were expressed at low levels in ML phase, whereas genes in cluster 14 had very high transcripts in ML phase. Cluster 5 contains genes involved in multiple cellular and metabolic processes, whereas cluster 14 genes are involved predominantly in synthesis of ribosomal proteins. Clusters 12-14 contain genes encoding RNA polymerase subunits (gbs0084, gbs0105, gbs0156/7, gbs0302) that are down regulated from -2.3 to -10 times, which likely indicates a slowing of gene transcription. RpoD (gbs1496, encoding the major $\sigma 70$ ) is also down regulated $(\sim-3 \times)$. The RpoE subunit (gbs0105) plays a role in the development of sepsis during GBS infection [22], and its down regulation during growth might have consequences for GBS virulence.

\section{$S$ phase related genes}

We identified a group of known stress response genes present in clusters 1-4 that were significantly up-regulated in S phase, including $h r c A, \operatorname{grpE}, \operatorname{dnaK}$ (gbs0094-96), clpE, and $c l p L$ (gbs0535 and gbs1376). Transcription of genes putatively involved in the stress response such as Gls24 and universal stress response family proteins gbs1202/ 1204, gbs 1721, and gbs 1778 were also elevated in S phase compared to ML phase (Table 1).

Two apparent operons responsible for arginine/ornithine transport and metabolism were also among the group of 
Table I: Fold changes in transcript levels of GBS genes.

\begin{tabular}{|c|c|c|}
\hline Gene & Fold change in S phase (S/ML ratio) & Putative function \\
\hline \multicolumn{3}{|c|}{ S phase related genes } \\
\hline hrcA, grpE, dnaK (gbs0094-96), & +4 to +7.5 & Stress response \\
\hline$c l p E$, and $c l p L$ (gbs0535 and gbs|376) & +4.5 and +7.5 & Chaperones \\
\hline gbs I 202/I204, gbs I $72 \mid$, gbs 1772 & +30 to +64 & $\begin{array}{l}\text { Putative stress response proteins from Gls } 24 \text { and } \\
\text { universal stress response families }\end{array}$ \\
\hline gbs2083-2085 & +350 to over +1000 & $\begin{array}{l}\text { arginine/ornithine antiporter, carbamate kinase, } \\
\text { ornithine carbamoyltransferase }\end{array}$ \\
\hline gbs $2122-2126$ & +55 to +150 & $\begin{array}{l}\text { arginine deiminase ornithine carbamoyltransferase, } \\
\text { arginine/ornithine antiporter carbamate kinase }\end{array}$ \\
\hline$g / p K D F($ gbs0263-5) & +45 to +63 & $\begin{array}{l}\text { putative operon responsible for glycerol uptake and } \\
\text { utilization. }\end{array}$ \\
\hline \multicolumn{3}{|c|}{ Nutrient utilization and energy metabolism } \\
\hline fba gbs0I 25 & +2.2 & fructose-bisphosphate aldolase \\
\hline plr gbs 1811 & +3.1 & glyceraldehyde 3P-dehydrogenase \\
\hline pgk gbs 1809 & +2.8 & phosphoglycerate kinase \\
\hline eno gbs0608 & +2.5 & enolase \\
\hline$a c o A B$ (gbs 0895-0896) & +4 & pyruvate dehydrogenase \\
\hline Idh gbs0947 & +2.8 & L-lactate dehydrogenase \\
\hline \multicolumn{3}{|c|}{ Regulators and signal transduction systems } \\
\hline gbs $1671 / 2$ & -2 & TCS CovR/S \\
\hline gbs $1908 / 9$ & $+10 / 14$ & TCS, homolog of GAS SpyI I06/7 (SF370) \\
\hline gbs $1934 / 5$ & $+5 /+5$ & TCS, homolog of Spy 106I/2 (SF370) \\
\hline gbs208I/2 & $-2.3 /-1.7$ & TCS, putative arginine utilization regulator \\
\hline gbs2086/7 & $2.5 / 2.6$ & TCS, putative arginine utilization regulator \\
\hline gbs $1834 / 5$ & $-7.5 /-11.7$ & TCS \\
\hline gbs | 397/8 & $-7 /-5.8$ & TCS \\
\hline gbs0597/8 & $-5 /-8.5$ & TCS \\
\hline gbs012I/2 & $-2 / 1$ & TCS \\
\hline gbs0298/9 & $-3 /-1.8$ & TCS \\
\hline gbs0309/10 & $-3.3 /-3$ & TCS \\
\hline
\end{tabular}


Table I: Fold changes in transcript levels of GBS genes. (Continued)

\begin{tabular}{|c|c|c|}
\hline gbs0429/30 & $-2.4 /-1.6$ & TCS \\
\hline gbs0963/4 & $+1.7 /+2$ & TCS \\
\hline gbs $1019 / 20$ & $-1.9 /-1.9$ & TCS \\
\hline gbs $1947 / 8$ & $-3 /-2.4$ & TCS \\
\hline gbs I943/4 & $-2.1 /-2.7$ & TCS \\
\hline gbs0680 & +3.1 & CсpA \\
\hline gbs019I & +50 & $\begin{array}{l}\text { putative transcriptional antiterminator of the BgIG } \\
\text { family }\end{array}$ \\
\hline gbs0469 & -34 & Regulator of unknown function \\
\hline relA (gbs | 928) & -50 & GTP pyrophosphokinase \\
\hline $\operatorname{codY}$ (gbs |7|9;) & -8 & Global regulator \\
\hline luxS (gbs0294) & -3 & Quorum sensing \\
\hline mecA (gbs0।35) & -20 & Global regulator of competence \\
\hline \multicolumn{3}{|c|}{ Virulence factors } \\
\hline gbs 1420 & +6.26 & choline-binding protein \\
\hline gbs I 539 & +4.67 & cell wall anchored protein \\
\hline gbs 1929 & +5.48 & putative nucleotidase \\
\hline gbs I I 43 & +2.61 & cell wall anchored protein \\
\hline gbs045I & -2 & paralog of C5A peptidase precursor \\
\hline gbs I 104 & -6.15 & cell wall anchored protein \\
\hline gbs 1529 & -11 & putative fibronectin binding protein \\
\hline gbs 0850 & -3 & putative fibronectin binding protein \\
\hline gbs | 307 & -3 & laminin binding protein \\
\hline gbs 1926 & -3 & putative laminin binding protein \\
\hline gbs $1475 / 6$ & -5.5 & sortases \\
\hline gbs0644-0654 & -1.6 to -2.8 & hemolysin \\
\hline gbs 1061-1076 & -2.5 to -12.9 & pathogenicity island IX \\
\hline gbs I 233-1247 & -3 to -12.4 & capsule synthesis \\
\hline cpsX gbs 1250 & 4.4 & capsule synthesis regulator \\
\hline
\end{tabular}


Table I: Fold changes in transcript levels of GBS genes. (Continued)

\begin{tabular}{lll}
\hline gbs $1478 / 9$, gbs $|48|$, gbs $\mid 484 / 5$, gbs $\mid 492-1494$ & -3 to -12 & Putative group B antigen \\
\hline Cfa gbs 2000 & +11.6 & CAMP factor
\end{tabular}

The table presents fold change in S phase in comparison with ML phase, classification into functional categories, and putative function.

Table 2: Putative CcPA binding sites in promoter regions of genes encoded by S. agalactiae NEM3 16 genome.

\begin{tabular}{|c|c|c|c|c|c|c|}
\hline Match & Start (nt) & End (nt) & Homology with consensus(\%) & ORF number & Name & Putative function \\
\hline TGACAACGGTAAAA & 16111 & 16124 & 92 & gbsr00I & & I6S ribosomal RNA \\
\hline TGAAAACGCTTTAA & 48894 & 48907 & 92 & gbs0032 & & $\begin{array}{l}\mathrm{N} \text {-acetylmannosamine-6-phosphate 2- } \\
\text { epimerase }\end{array}$ \\
\hline TGACAAGGATGTCA & 65156 & 65169 & 92 & gbs0049 & ruvB & Holliday junction DNA helicase ruvB \\
\hline TTAAAGCGCTTTCA & 69320 & 69333 & 92 & gbs 0053 & adh2 & Alcohol dehydrogenase \\
\hline TGTAAACGATTACA & 72238 & 72251 & 100 & gbs0054 & adhA & Alcohol dehydrogenase \\
\hline TGGGAACGGTTTCA & 130310 & 130323 & 92 & gbs0l19 & & $A B C$ transporter permease protein \\
\hline TGTAATCGCTTACT & 130334 & 130347 & 92 & gbs0II9 & & $A B C$ transporter permease protein \\
\hline TATTAACGTTAACA & 142634 & 142647 & 92 & gbs0I30 & & Membrane protease protein family \\
\hline TGTCAACTATATCA & 176297 & 176310 & 92 & gbs0I55 & & $\begin{array}{l}\text { Multimodular transpeptidase- } \\
\text { transglycosylase PBP IB }\end{array}$ \\
\hline TGTAATCGTTTACA & 209972 & 209985 & 100 & gbs0189 & & $\begin{array}{l}\text { PTS system, trehalose-specific IIBC } \\
\text { component }\end{array}$ \\
\hline TGTAAACGGTTACT & 214120 & 214133 & 92 & gbs019I & & Transcription antiterminator, Bg|G family \\
\hline TGAAAAAGGTAACA & 243786 & 243799 & 92 & gbs0227 & & pseudogene \\
\hline TGTTACCGTTTTCA & 284183 & 284196 & 100 & gbs0266 & & NADH peroxidase \\
\hline TGAAAGCGGTTATA & 349577 & 349590 & 92 & gbs0326 & & Ribosome-associated factor $Y$ \\
\hline AGAAAGCGTTAACA & 349601 & 349614 & 92 & gbs0326 & & Ribosome-associated factor $Y$ \\
\hline TTAAAACGTTTTCA & 375767 & 375780 & 92 & gbs0348 & $\operatorname{manL}$ & $\begin{array}{l}\text { PTS system, mannose-specific IIAB } \\
\text { component }\end{array}$ \\
\hline TGATACCGTTCACT & 480733 & 480746 & 92 & gbs0452 & & $\begin{array}{l}\text { alpha-L-Rha alpha-I,3-L- } \\
\text { rhamnosyltransferase }\end{array}$ \\
\hline TAATAACGTTAACA & 515726 & 515739 & 92 & gbs0493 & & Hypothetical protein \\
\hline TGAAAACATTTACA & 540267 & 540280 & 92 & gbs0520 & typA & GTP-binding protein TypA BipA \\
\hline TGACACCGTTTTCA & 592276 & 592289 & 100 & gbs0569 & & Acetoin dehydrogenase \\
\hline AGATAGCGGTCACA & 608177 & 608190 & 92 & gbs0583 & & Adenosine deaminase \\
\hline TGATATCGCTTTCA & 638255 & 638268 & 100 & gbs0615 & & Class B acid phosphatase \\
\hline
\end{tabular}


Table 2: Putative CcpA binding sites in promoter regions of genes encoded by S. agalactiae NEM3 I 6 genome. (Continued)

\begin{tabular}{|c|c|c|c|c|c|c|}
\hline TGAAAGTGTTGACA & 661185 & 661198 & 92 & gbs0644 & cyIX & Hypothetical protein \\
\hline TAAAAGCGTTTACA & 684988 & 685001 & 92 & gbs0669 & & SUGAR SODIUM SYMPORTER \\
\hline AGATAACGGTTACA & 690270 & 690283 & 92 & gbs 0673 & & 4-Hydroxy-2-oxoglutarate aldolase \\
\hline TAAAAACGCTAACA & 837159 & 837172 & 92 & gbs0813 & & Glycerate kinase \\
\hline TTAGAGCGTTTTCA & 870536 & 870549 & 92 & gbs0844 & udk & Uridine kinase \\
\hline TGTAAGCCTTGTCA & 879217 & 879230 & 92 & gbs0852 & & Hypothetical protein \\
\hline TGTAAACCATCTCA & 903332 & 903345 & 92 & gbs0875 & atpE & ATP synthase $C$ chain \\
\hline TGAAAACGTAATCA & 903356 & 903369 & 92 & gbs0875 & atpE & ATP synthase $C$ chain \\
\hline TGTTAACGCTATTA & 913902 & 913915 & 92 & gbs0887 & phet & Acetyltransferase, GNAT family \\
\hline TGAAAACCGTTTCA & 981187 & 981200 & 92 & gbs0940 & & I6S rRNA m(2)G I 207 methyltransferase \\
\hline TGAAAGCGTTTATA & $1 \mid 45634$ & II 45647 & 92 & gbs 1100 & PgmA & Phosphoglucomutase \\
\hline AGAAAACGGTATCA & 1157589 & 1157602 & 92 & gbs 1112 & apbE & $\begin{array}{l}\text { Iron-sulfur cluster assembly repair } \\
\text { protein ApbE }\end{array}$ \\
\hline TAATACCGTTATCA & $|20022|$ & 1200234 & 92 & gbs 1156 & & $\mathrm{Na}+$ driven multidrug efflux pump \\
\hline TGAAATCGATTACA & 1235422 & 1235435 & 100 & gbs 1192 & gabD & $\begin{array}{l}\text { Succinate-semialdehyde dehydrogenase } \\
{[\mathrm{NADP}+]}\end{array}$ \\
\hline TGTAAAGGTTTTCA & 1237447 & 1237460 & 92 & gbs II95 & ska & streptokinase \\
\hline TGTAAACGTTTTTA & 1248933 & 1248946 & 92 & gbs 1200 & & Hydrolase (HAD superfamily) \\
\hline TTTAAACGCTATCA & 1314589 & 1314602 & 92 & gbs 1273 & $\mathrm{rmIA}$ & $\begin{array}{l}\text { Glucose-I-phosphate } \\
\text { thymidylyItransferase }\end{array}$ \\
\hline TGAAACCGGTTTGA & 1337103 & 1337116 & 92 & gbs 1293 & & $\begin{array}{l}\text { glycerophosphoryl diester } \\
\text { phosphodiesterase }\end{array}$ \\
\hline TGAAAGCTCTGACA & 1489796 & 1489809 & 92 & gbs 1437 & & Transcriptional regulators, Lys $R$ family \\
\hline TGACAGCGCAATCA & 1492240 & 1492253 & 92 & gbs $144 \mid$ & capA & Capsule biosynthesis protein capA \\
\hline TGTAACCGTTTTTA & 1518448 & $15|846|$ & 92 & gbs 1468 & $\mathrm{pflC}$ & Pyruvate formate-lyase activating enzyme \\
\hline TGTAACCGCTTTCT & 1742894 & 1742907 & 92 & gbs 1684 & & Zn-dependent alcohol dehydrogenase \\
\hline TGTACACGATATCA & 1749143 & 1749156 & 92 & gbs 1689 & & $\begin{array}{l}A B C \text { transporter substrate-binding } \\
\text { protein }\end{array}$ \\
\hline TGAAAACCCTAACA & 1752507 & 1752520 & 92 & gbs 1694 & & Dihydroxyacetone kinase \\
\hline TGACAACGTTAAAA & 1824783 & 1824796 & 92 & gbs 1764 & mutS2 & DNA mismatch repair protein mutS \\
\hline TGTAAGCGTTTTAA & 1920050 & 1920063 & 92 & gbs 1856 & ulaA & $\begin{array}{l}\text { PTS system, 3-keto-L-gulonate specific IIC } \\
\text { component }\end{array}$ \\
\hline
\end{tabular}


Table 2: Putative CcpA binding sites in promoter regions of genes encoded by S. agalactiae NEM3 I 6 genome. (Continued)

\begin{tabular}{lllllll}
\hline TGACACCGGTATAA & 1925222 & 1925235 & 92 & gbs 1862 & Amino acid ligase family protein \\
\hline TTATACCGTTTTCA & 1929838 & 1929851 & 92 & gbs 1865 & hslO & 33 kDa chaperonin \\
\hline TGTAAACGTTTTTA & 1939040 & 1939053 & 92 & gbs 1874 & ahpC & Peroxiredoxin \\
\hline TGTAATCTCTTACA & 1946899 & 1946912 & 92 & gbs 1875 & ahpF & Peroxiredoxin reductase (NAD(P)H) \\
\hline TTATAGCGCTTTCA & 1957716 & 1957729 & 92 & gbs 1879 & pepO & Oligoendopeptidase O \\
\hline TGATAACTATGTCA & 1990172 & 1990185 & 92 & gbs 1918 & lacA.l & $\begin{array}{l}\text { Galactose-6-phosphate isomerase lacA } \\
\text { subunit }\end{array}$ \\
\hline TGAAAGCGGTTTAA & 2014283 & 2014296 & 92 & gbs 1939 & PTS system, mannose fructose family IIA \\
\hline TGTAAACGCTTTTA & 2101628 & 2101641 & 92 & gbs2026 & udp & Uridine phosphorylase \\
\hline TGATATCGTAATCA & 2130043 & 2130056 & 92 & gbs2055 & argR2 & Arginine repressor, argR \\
\hline AGATATCGCTTTCA & 2157836 & 2157849 & 92 & gbs2085 & Ornithine carbamoyltransferase
\end{tabular}

Genome was searched using BLAST algorithm (CLC DNA Workbench 4) with cre consensus sequence: TGWNANCGNTNWCA (N any nucleotide, W indicates adenine or thymine) and accuracy $90 \%$. Start/End coordinates according to genome sequence

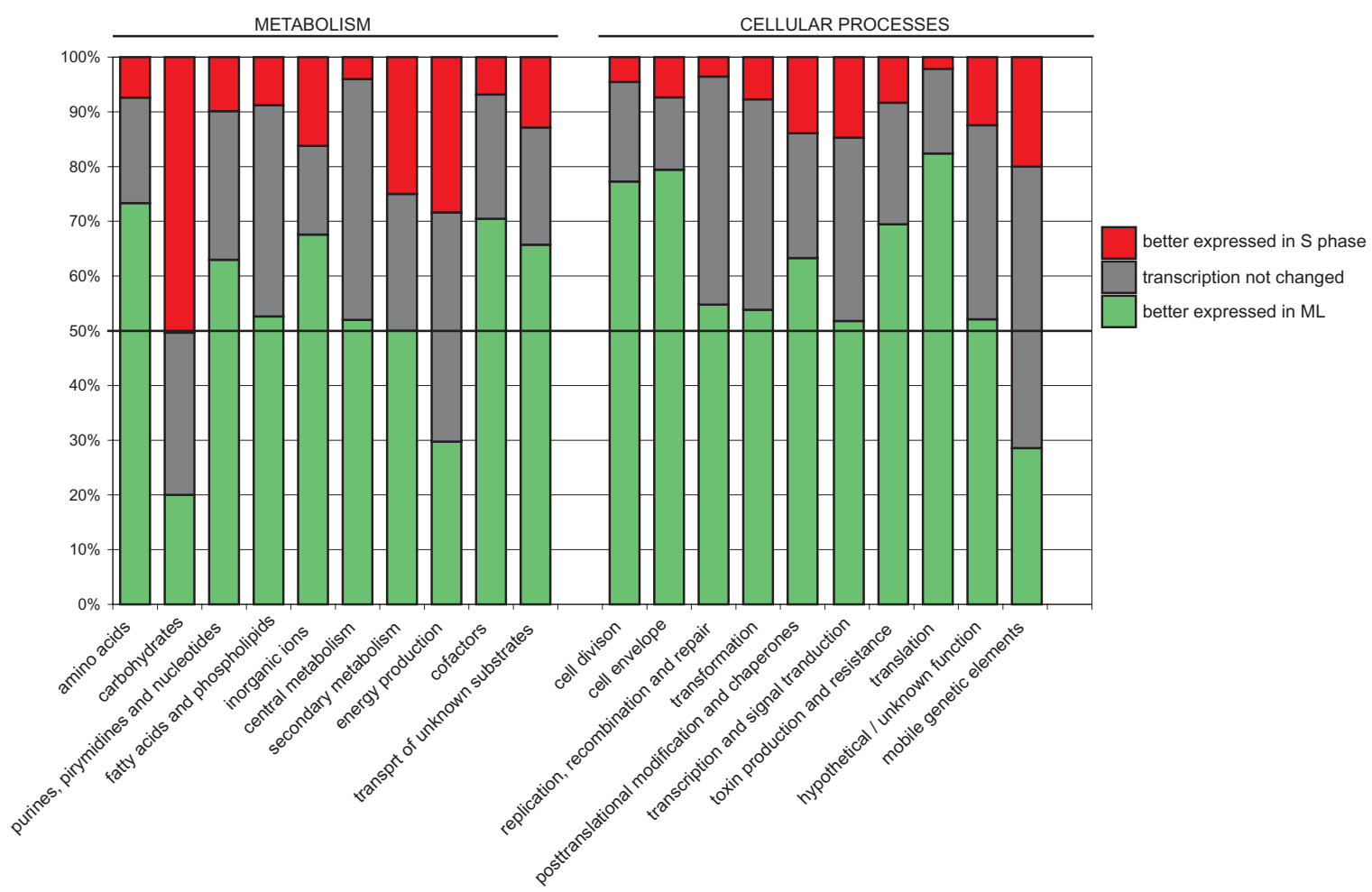

\section{Figure 3}

Trends in transcript levels of genes involved in metabolism and cellular processes. I,994 of GBS transcripts represented on the chip were grouped into functional categories (see Table I and Additional file 2). The total number of genes in each category is shown as $100 \%$ and the number of transcripts more highly expressed in ML or S phase and transcripts with unchanged expression are presented as a fraction of the $100 \%$. 
highly transcribed S phase genes. One operon (gbs20832085) encodes an arginine/ornithine antiporter, carbamate kinase, and ornithine carbamoyltransferase, respectively, and is up-regulated 350 to $>1,000$ times. The second operon (gbs2122-2126) encodes arginine deiminase, a second ornithine carbamoyltransferase, a second arginine/ornithine antiporter, and another carbamate kinase and is up-regulated $~ 55$ to 150 times. Enzymes encoded by genes in these apparent operons are involved in arginine fermentation via the arginine deiminase pathway. They allow GBS to use arginine as an energy source after simple carbohydrates are exhausted from the medium, as would occur during stationary phase. On the other hand, activation of arginine deiminase pathway might have protective function against acidic conditions in a way similar to oral Streptococci [23] as we observed decrease of $\mathrm{pH}$ from about 7.9 to 5.5 between ML and S growth phases.

Metabolic changes toward the utilization of increasingly complex nutrient and carbon sources (see below) can be reflected by changes in utilization of simple carbohydrates (drop in the glucose concentration in the medium from $\sim 300 \mathrm{mg} / \mathrm{ml}$ in $\mathrm{ML}$ to non detectable level in S) and by changes in transcription of the glpKDF (gbs0263-5, +45 to +63 times), a putative operon responsible for glycerol uptake and utilization.

\section{Trends in expression of genes involved in nutrient utilization and energy metabolism}

In contrast to genes involved in other aspects of GBS metabolism and physiology, the only genes significantly up-regulated in S phase compared to ML were involved in carbohydrate metabolism (Figure 3). For example, we observed increased levels of certain glycolytic enzymes such as fructose-bisphosphate aldolase (gbs0125), glyceraldehyde 3P-dehydrogenase (gbs1811), phosphoglycerate kinase (gbs1809), enolase (gbs0608), pyruvate dehydrogenase $(a c o A B)$, and L-lactate dehydrogenase (gbs0947) (Table 1). This finding is similar to the results reported recently by Chaussee et al [19] showing that transcripts encoding proteins involved in carbohydrate utilization and transport were more abundant in S phase, presumably to maximize carbohydrate utilization. The authors suggested that increased transcription of genes involved in central metabolism and sequential utilization of more complex carbohydrates might be a particularly useful adaptation during infection of tissues where the concentration of carbohydrates is low [19]. In GAS, transcripts of genes involved in transport and metabolism of lactose, sucrose, mannose, and amylase were also more abundant during the stationary phase of growth [19], similar to our findings in GBS (Additional file 2). Similar to links between carbohydrate metabolism and virulence in GAS [21], also carbohydrate metabolism in GBS might be connected to strain invasiveness and strain tissue-disease specificity [24].

\section{Changes in expression of regulators and signal transduction systems}

TCSs are especially important in the control of global gene expression, especially in the absence of alternative sigma factors. Of the multiple TCSs in GBS, only $\operatorname{cov} R / S$ (gbs $1671 / 2$ ) has been well characterized. CovR/S in GBS controls expression of multiple virulence factors, such as hemolysin, CAMP factor, and multiple adhesins [25]. The transcript levels of $\operatorname{cov} R / S$ are down regulated in $S$ phase, which may be responsible for the observed changes in transcription of virulence factors such as $c y l$ genes encoding hemolysin. However, because the putative effect of CovRS on the camp and $c y l$ genes seems to be opposite to those observed in covRS NEM316 mutant [26] it suggests that these genes are under influence of additional regulators.

Several other GBS genes encoding putative TCSs and regulators had significant changes in transcript levels during the growth phases studied. For example, transcript levels of gbs1908/9 increased 10/14 times between ML and S phases. The GAS homologs (M5005_Spy_0830/1 in strain MGAS5005 and Spy1106/7 in strain SF370) regulate an operon located downstream that encodes NAD-dependent malic enzyme and malate-sodium symport. In a $\Delta \mathrm{M} 5005$ Spy_0830 deletion strain, the transcript of these downstream genes is decreased 23/40 times [12], indicating positive regulation. Organization of this chromosomal region in GBS is very similar to GAS, and gbs1906 and gbs1907 encode putative homologues to the GAS NAD-dependent malic enzyme and malate-sodium symport proteins, respectively. Genes gbs1906/7 are 63/81 times up-regulated in $S$ phase; therefore this operon appears to be regulated in a similar manner in both GBS and GAS.

The transcript level of another GAS TCS homolog, gbs1934/5, is also elevated. Gbs1934/5 has close identity ( 85\%) with GAS M5005_Spy_0785/6 (Spy1061/2 in strain SF370), a TCS that has been implicated in the regulation of the mannose/fructose-specific phosphotransferase (PTS) system [12]. Interestingly, in GBS there is also a homolog of this PTS system located directly downstream of gbs1934/5 that is highly up-regulated (46.5 to 468 times) in $S$ phase. Therefore, based on gene position, homology, and transcription regulation patterns, it is reasonable to speculate that these genes function similarly in GBS and GAS.

The possible functions of other TCSs can be inferred from their position. Two sets of TCSs are located directly upstream (gbs2081/2) and downstream (gbs2086/7) of 
an operon with arginine catabolism genes that are highly up regulated in $S$ phase (see above). The transcript levels of both TCSs change dynamically during growth (Table 1 and Additional file 2). It is probable that genes encoding arginine catabolism proteins might be under tight control of both or either TCS. However, this needs to be confirmed experimentally. Thus, our transcript profiling results are consistent with the hypothesis that in the absence of global response gene regulation medicated by alternative sigma factors, GBS uses multiple TCSs as key mediators regulating the response to changes in the environment (Table 1).

Among putative regulators of unknown function, the highest changes were observed for gbs0191 encoding a transcriptional antiterminator of the BglG family $(+50$ times, putative CcpA binding site) and gbs0469 (-34 times). Surprisingly, we observed down regulation of expression of other global regulators that are associated with stress and the stringent response to starvation. These include the gene relA (gbs1928) that encodes a putative GTP pyrophosphokinase (-50), $\operatorname{cod} Y$ (gbs1719; -8), the cell density dependent regulator luxS (-3), and the putative mecA (gbs0135) homolog (-20). This result was unexpected given that relA, $\operatorname{cod} Y$, and luxS are up-regulated in $S$ phase GAS [19].

\section{Transcripts of proven or putative virulence genes}

We observed changes in the transcript level of multiple genes encoding proteins with a carboxyterminus cell-wall anchoring motif. The putative location off the proteins on the cell surface suggests that they may play a role in GBS virulence or pathogen-host interaction. Four transcripts were significantly up-regulated in S phase gbs $1420(+6.3)$, encoding choline-binding protein, gbs1539 $(+4.7)$ and gbs1929 (+5.5) encoding a putative nucleotidase, and gbs1143 (+2.6). We also observed down regulation in S phase of transcripts for several cell wall anchored proteins including a paralog of C5A peptidase precursor gbs0451 ($2)$, gbs1104 (-6.2), putative adhesin gbs1529 (-11) and fbp (gbs0850, -3), and putative laminin binding proteins (gbs1307, gbs1926; -3). Down regulation in S phase of proteins involved in bacterial attachment is consistent with results reported for GAS $[14,15,19]$. It is believed that several cell surface proteins are produced during the initial stages of infection to promote adhesion, and later are down-regulated to avoid immune detection.

Other known virulence factors of GBS that showed decreased transcription in $S$ phase included an operon encoding hemolysin (gbs0644-0654), genes encoded on the putative pathogenicity island IX (gbs1061-1076), the putative group B antigen (gbs1478/9, gbs1481, gbs1484/ 5, gbs1492-1494), and genes involved in capsule synthesis (gbs1233-1247). The putative kinase cpsX (gbs1250) was upregulated 4.4 times (Table 1). Down regulation of capsule and putative and known surface antigens is known to occur in GAS $[14,15,19]$. For example, capsule, an antiphagocytic factor, is expressed during establishment of GAS infection and is later down-regulated once the infection is established $[14,15]$. Our results imply a similar scenario could be occurring in GBS. The only transcript encoding a proven virulence factor that was increased in $S$ phase was CAMP factor $(+11.6, c f a$, gbs2000).

\section{Conclusion}

Our results demonstrate that GBS gene transcript levels are highly dynamic throughout the growth cycle in vitro, likely reflecting exposure to an environment that is altering significantly during growth. The organism activates genes involved in metabolism of nutrients and carbon sources other than glucose such as complex carbohydrates and arginine and protect against changing $\mathrm{pH}$. GBS slows down cell division and decreases transcription and translation. Production of virulence factors involved in establishment of the infection is reduced during growth. The global changes of transcript profiles we identified in GBS grown in rich medium are similar to patterns exhibited by GAS. Our results provide new information useful for the study of pathogen-host interactions and gene regulation in pathogenic bacteria.

\section{Authors' contributions}

IS performed the research, IS and JMM analyzed the data and wrote the paper.

\section{Additional material}

\section{Additional File 1 \\ Supplemental table 1- Normalized hybridization values. File contains normalized hybridization values for each array used in the study. ML-mid logarithmic, LL-late logarithmic, ES-early stationary, S-stationary. P- "present" signal (detected in sample), M-"marginal " signal, A-"absent" signal (not detected) \\ Click here for file \\ [http://www.biomedcentral.com/content/supplementary/1471- 2180-9-32-S1.xls] \\ Additional File 2 \\ Supplemental table 2 Changes in transcription of 1,994 transcripts present on array (S/ML ratio). Green-genes down regulated in $S$ phase, Red - genes up regulated in S phase, Gray - P values below 0.05. Click here for file \\ [http://www.biomedcentral.com/content/supplementary/1471- 2180-9-32-S2.xls]}

\section{Acknowledgements}

Authors would like to thank Kathryn Stockbauer for critical reading of the manuscript. 


\section{References}

I. Commichau FM, Forchhammer K, Stulke J: Regulatory links between carbon and nitrogen metabolism. Curr Opin Microbiol 2006, 9:167-172

2. Gruber TM, Gross CA: Multiple sigma subunits and the partitioning of bacterial transcription space. Annu Rev Microbiol 2003, 57:44|-466.

3. Laub MT, Goulian M: Specificity in two-component signal transduction pathways. Annu Rev Genet 2007, 4 I: | 2 | - | 45.

4. Nascimento MM, Lemos JA, Abranches J, Lin VK, Burne RA: Role of RelA of Streptococcus mutans in global control of gene expression. J Bacteriol 2008, 190:28-36.

5. Storz G: An expanding universe of noncoding RNAs. Science 2002, 296: 1260-1263.

6. Xavier KB, Bassler BL: LuxS quorum sensing: more than just a numbers game. Curr Opin Microbiol 2003, 6:191-197.

7. Glaser P, Rusniok C, Buchrieser C, Chevalier F, Frangeul L, Msadek T, Zouine M, Couve E, Lalioui L, Poyart C, Trieu-Cuot P, Kunst F: Genome sequence of Streptococcus agalactiae, a pathogen causing invasive neonatal disease. Mol Microbiol 2002 45: $1499-1513$

8. Opdyke JA, Scott JR, Moran CP Jr: A secondary RNA polymerase sigma factor from Streptococcus pyogenes. Mol Microbiol 200I, 42:495-502.

9. Tettelin H, Masignani V, Cieslewicz MJ, Donati C, Medini D, Ward NL, Angiuoli SV, Crabtree J, Jones AL, Durkin AS, Deboy RT, Davidsen TM, Mora M, Scarselli M, Ros I, Peterson JD, Hauser CR, Sundaram JP, Nelson WC, Madupu R, Brinkac LM, Dodson RJ, Rosovitz MJ, Sullivan SA, Daugherty SC, Haft DH, Selengut J, Gwinn ML, Zhou L, Zafar N, Khouri H, Radune D, Dimitrov G, Watkins K, O'Connor KJ Smith S, Utterback TR, White O, Rubens CE, Grandi G, Madoff LC, Kasper DL, Telford JL, Wessels MR, Rappuoli R, Fraser CM: Genome analysis of multiple pathogenic isolates of Streptococcus agalactiae: implications for the microbial "pangenome". Proc Natl Acad Sci USA 2005, I 02: I 3950-I 3955.

10. Barnett TC, Bugrysheva JV, Scott JR: Role of mRNA stability in growth phase regulation of gene expression in the group $A$ streptococcus. J Bacteriol 2007, 189: | 866-|873.

II. Hondorp ER, Mclver KS: The Mga virulence regulon: infection where the grass is greener. Mol Microbiol 2007, 66: $1056-1065$

12. Sitkiewicz I, Musser JM: Expression microarray and mouse virulence analysis of four conserved two-component gene regulatory systems in group a streptococcus. Infect Immun 2006 , 74: $|339-| 35 \mid$

13. Shelburne SA III, Sumby P, Sitkiewicz I, Granville C, DeLeo FR, Musser JM: Central role of a bacterial two-component gene regulatory system of previously unknown function in pathogen persistence in human saliva. Proc Natl Acad Sci USA 2005 I02:16037-16042.

14. Graham MR, Virtaneva K, Porcella SF, Barry WT, Gowen BB, Johnson CR, Wright FA, Musser JM: Group A Streptococcus transcriptome dynamics during growth in human blood reveals bacterial adaptive and survival strategies. Am J Pathol 2005, I 66:455-465.

15. Graham MR, Virtaneva K, Porcella SF, Gardner DJ, Long RD, Welty DM, Barry WT, Johnson CA, Parkins LD, Wright FA, Musser JM: Analysis of the transcriptome of group A Streptococcus in mouse soft tissue infection. Am J Pathol 2006, I 69:927-942.

16. Johri AK, Margarit I, Broenstrup M, Brettoni C, Hua L, Gygi SP, Telford JL, Grandi G, Paoletti LC: Transcriptional and proteomic profiles of group B Streptococcus type $V$ reveal potential adherence proteins associated with high-level invasion. Infect Immun 2007, 75:|473-|483.

17. Keefe GP: Streptococcus agalactiae mastitis: a review. Can Vet I 1997, 38:429-437.

18. Muller AE, Oostvogel PM, Steegers EA, Dorr PJ: Morbidity related to maternal group B streptococcal infections. Acta Obstet Gynecol Scand 2006, 85: 1027-1037.

19. Chaussee MA, Dmitriev AV, Callegari EA, Chaussee MS: Growth phase-associated changes in the transcriptome and proteome of Streptococcus pyogenes. Arch Microbiol 2008 , I 89:27-4I.

20. Chomczynski P, Sacchi N: Single-step method of RNA isolation by acid guanidinium thiocyanate-phenol-chloroform extraction. Anal Biochem 1987, I62:156-159.
21. Shelburne SA III, Keith D, Horstmann N, Sumby P, Davenport MT, Graviss EA, Brennan RG, Musser JM: A direct link between carbohydrate utilization and virulence in the major human pathogen group A Streptococcus. Proc Natl Acad Sci USA 2008 105:1698-1703.

22. Jones AL, Needham RH, Rubens CE: The Delta subunit of RNA polymerase is required for virulence of Streptococcus agalactiae. Infect Immun 2003, 7 I:40 I I-40 I 7.

23. Quivey RG, Kuhnert WL, Hahn K: Genetics of acid adaptation in oral streptococci. Crit Rev Oral Biol Med 200I, I 2:30I-3 |4.

24. Domelier AS, van dM-M, Grandet A, Mereghetti L, Rosenau A, Quentin R: Loss of catabolic function in Streptococcus agalactiae strains and its association with neonatal meningitis. J Clin Microbiol 2006, 44:3245-3250.

25. Lamy MC, Zouine M, Fert J, Vergassola M, Couve E, Pellegrini E, Glaser P, Kunst F, Msadek T, Trieu-Cuot P, Poyart C: CovS/CovR of group $B$ streptococcus: a two-component global regulatory system involved in virulence. Mol Microbiol 2004, 54: I 250- I 268.

26. Jiang SM, Ishmael N, Hotopp JD, Puliti M, Tissi L, Kumar N, Cieslewicz MJ, Tettelin H, Wessels MR: Variation in the group B Streptococcus CsrRS regulon and effects on pathogenicity. J Bacteriol 2008, 190:1956-1965.
Publish with Biomed Central and every scientist can read your work free of charge

"BioMed Central will be the most significant development for disseminating the results of biomedical research in our lifetime. "

Sir Paul Nurse, Cancer Research UK

Your research papers will be:

- available free of charge to the entire biomedical community

- peer reviewed and published immediately upon acceptance

- cited in PubMed and archived on PubMed Central

- yours - you keep the copyright
BioMedcentral 